\title{
Association of the Monocyte to HDL Cholesterol Ratio With Coronary Artery Disease Severity in Patients With Acute Coronary Syndrome
}

\author{
Dicky Yulianda*1, Abdullah A. Siregar ${ }^{1}$, Zulfikri Mukhtar ${ }^{1}$, Refli Hasan ${ }^{1}$, \\ Harris Hasan ${ }^{1}$, Cut A. Andra ${ }^{1}$
}
${ }^{1}$ Department of Cardiology and Vascular Medicine, University of Sumatera Utara, Adam Malik Hospital, Medan, Indonesia

\begin{abstract}
Background : Monocytes and tissue macrophages play a pivotal role in atherosclerotic plaque formation. HDL cholesterol has an anti-inflammatory effects and can inhibite monocyte activation. The ratio of monocyte count/HDL cholesterol (MHR) is a parameter that has recently been studied and can widely used and also has a value of prognosis. The RMH predictive value for assessing the severity of coronary artery has not been widely studied. This study aims to evaluate whether the MHR value can be a predictor of the severity of coronary artery lesions in patients with acute coronary syndromes (ACS).

Methods : This retrospective cohort study of 97 patients with ACS undergoing coronary angiography and treatment at Adam Malik Hospital from January 2015 - April 2018. Patients were divided into two groups based on Gensini score, severe coronary lesions (Gensini $\geq 30$ ) and mild coronary lesions (Gensini < 30). Bivariate, multivariate and correlation analysis were performed to find the relationship between MHR and Gensini score as well as finding meaningful RMH cutoff points. The p value $<0.05$ was considered statistically significant.

Results : Of the 97 patients with ACS, 48 subjects (49.5\%) were scored with a high Gensini score and 49 subjects $(50.5 \%)$ with low Gensini score. The ROC curve analysis obtained MHR cutoff value in predicting the severity of coronary artery lesion was 0.021 (AUC 0.725 , $95 \%$ CI $0.623-0.827, \mathrm{p}<0.046$ )with a sensitivity of $70.3 \%$ and specificity of $45 \%$. This study found a significant relationship but with a weak correlation between MHR value and Gensini score $(\mathrm{p}=0.006)(\mathrm{r}=0.252)$. Logistic regression analysis showed MHR value $\geq 0.021$ (OR 2.68, 95\% CI 1.069-6.716, $\mathrm{p}=0.035)$ along with moderate to high TIMI score (OR 4.682, 95\%CI $1.445-15.168, \mathrm{p}<0.01)$ became an independent factor for predicting the severity of coronary artery lesions.

Conclusion : There is a positive but weak correlation between the MHR value and the severity of coronary artery lesions in ACS patients. MHR value $\geq 0.021$ is an independent factor in predicting the severity of coronary artery lesions in patients with ACS.

Keywords : MHR, Gensini, ACS.
\end{abstract}

Dicky Yulianda et al /International Journal of ChemTech Research, 2018,11(10): 95-102. 


\section{Introduction}

In the last few decades, cardiovascular diseases are the main causes of death in the world. An estimated 17.7 million people died from cardiovascular diseases in 2015 and of these deaths, an estimated 7.4 million were due to coronary heart disease (CHD). ${ }^{1}$ ST-elevation myocardial Infarction (STEMI) is still the leading cause of death in the world with incidence in the United States in 2009 around one million people per year. ${ }^{2}$

Inflammation, oxidative stress, platelet activation and endothelial dysfunction are considered to have an important role in the development and progression of atherosclerosis. ${ }^{3,4}$ The activated inflammatory cells are found in coronary plaque in patients with acute coronary syndromes $(\mathrm{ACS})^{5}$, and signs of of inflammation were detected in the blood of an unstable angina pectoris (UAP) patients. ${ }^{6,7}$

Some types of inflammatory cells such as monocytes, lymphocytes, eosinophils, and neutrophils have been associated with $\mathrm{CHD}^{8}$ Monocyte cells are important component of the inflammatory process in atherosclerotic plaque. The high value of monocyte counts during the acute phase of acute myocardial infarction (AMI) is associated with the progression of the plaque itself ${ }^{9}$ and monocytosis has been assessed as an independent marker for CHD and AMI. ${ }^{10}$ At the time of the atherogenesis process, monocytes migrate to sub endothelial space and unite with lipoproteins into macrophages/foam cells. The ability of monocytes to migrate through the endothelium is important in the formation of lesions. Monocytes perform a better migration process in hypercholesterolemic conditions and the data show that circulating monocytes will differ in function in high cholesterol conditions.

The role of protection from high density lipoprotein cholesterol (HDL-C) in the general population has been described in various studies. The anti-atherosclerotic properties of HDL-C molecules play an important role in their function as an cholesterol carrier back to the liver. ${ }^{12,13} \mathrm{HDL}-\mathrm{C}$ particles have also been identified as anti-inflammatory and anti-oxidant, and have recently been studied to have a suppressive role in controlling monocyte activation as well as the proliferation and differentiation of monocyte progenitor cells. ${ }^{14,15}$

A new marker for cardiovascular disease that is often studied recently is the monocyte counts / HDLCratio (MHR) that have an effective prognosis and predictive value and are widely used laboratory parameters. MHR has been reported to be a new predictor and also a prognostic indicator of cardiovascular disease.${ }^{16}$ In the STEMI population, MHR is also described to be a predictor of the occurrence of stent thrombosis and major cardiovascular events as well as hospital mortality. ${ }^{17}$

However, there have been only a few studies conducted to look for an association of MHR with the severity of coronary artery lesions in patients with ACS.

\section{Methods}

This study was an observational study with a retrospective cohort design and single center to evaluate MHR value as a predictor of severity coronary artery lesions. This study was conducted by taking patient data with diagnosis of ACS undergoing coronary angiography procedures during hospitalization and never undergoing previous PCI or CABG procedures. Exclusion criteria were patients with incomplete medical record data, had previously been diagnosed with ACS, patients with a history of heart valve disease, congenital heart disease, cardiomyopathy or other heart disease, and patients with acute or chronic inflammatory diseases, malignancy, anemia, chronic renal failure or sepsis.

The researcher will examine the medical record of the ACS patient for history taking, physical examination, ECG, chest x-ray, laboratory examination and coronary angiography that have been done during hospitalization to make the diagnosis of ACS. All these data will be recorded carefully and systematically.

The Gensini scoring system was used for assessing the severity and extensiveness of coronary artery disease (CAD); in this system, the narrowing of the lumen of the coronary arteries is graded as follows: 1 for 1\%-25\% narrowing, 2 for 26\%-50\% narrowing, 4 for 51\%-75\% narrowing, 8 for 76\%-90\% narrowing, 16 for 91\%-99\% narrowing and 32 for a totally occluded artery. This score was then multiplied by a factor that accounts for the importance of the lesion's position in the coronary arterial anatomy. ${ }^{18}$ In this study will be divided into two groups based on the severity of coronary artery lesion, group 1 with Gensini score $\geq 30$ which describes as severe coronary artery lesions and group 2 with a Gensini score <30 that describes as mild coronary artery lesions. ${ }^{19}$ 
Routine haematological and biochemical tests were performed before coronary angiography. Complete blood specimen was taken when the patient first entered the emergency room. Serum lipid levels were measured after a 12-h fasting period. Fasting plasma glucose, lipid, and serum creatinine levels were calculated using standard methods. Blood specimens will be checked using the SYSMEX XT-4000 machine. Serum MHR is calculated by dividing the monocyte count by the HDL cholesterol level.

The categorical variable is presented with the number or frequency (n) and percentage (\%). The numerical variables are assigned with mean and standard deviation values for normally distributed data. Normality test in numerical variables of all subjects using one sample Kolmogorov Smirnov with $n>50$.Cut off point of numerical data was obtained from ROC. Comparison between dependent variable and independent variable was assessed by Pearson Chi Square. Correlation analysis is performed to assess the strength of the relationship expressed with $\mathrm{p}$ pearson. For samples that was found significant in the bivariate analysis test, the next step is a multivariate test with logistic regression. Statistical data analysis using statistical software, $p$ $<0.05$ is considered to be statistically significant.

\section{Results}

The total number of study subjects was 97 patients, consisting of 48 patients (49.5\%) with high Gensini score group and 48 patients (49.5\%) with low Gensini score group. The mean age of the high Gensini score group was $58 \pm 8$ years versus $54 \pm 8$ years in the other group, there was a statistically significant difference between these groups $(\mathrm{p}<0.014)$.

In a group with high Gensini score, there were 21 patients (43.8\%) with STEMI, 22 patients (45.8\%) with NSTEMI and 5 patients (10.4\%) with UAP.

In the laboratory examination, the mean monocyte value was $1.03 \pm 0.3$ in the group with high Gensini score and $0.7 \pm 0.2$ in the low Gensini score group, this was statistically significant $(\mathrm{p}<0.001)$. Significant statistical differences $(\mathrm{p}<0.001)$ were also found at mean MHR values, $0.033 \pm 0.015$ in groups with high Gensini score and $0.021 \pm 0.008$ in groups with low Gensini score.

Stratification of risk by using TIMI score was found by group with high Gensini score as many as 44 patients (91.7\%) with moderate to high TIMI score, whereas in group with low Gensini score found 16 patients $(32.7 \%)$ with low TIMI score ( $\mathrm{p}<0.003)$ (Table 1$)$.

Table 1.Baseline Characteristics Based on Severity of Coronary Artery Lesions

\begin{tabular}{|c|c|c|c|}
\hline Variable & $\begin{array}{l}\text { High Gensini Score } \\
(n=48)\end{array}$ & $\begin{array}{l}\text { Low Gensini Score } \\
(n=49)\end{array}$ & P value \\
\hline $\begin{array}{l}\text { Gender }(\mathrm{n}, \%) \\
\text { Male } \\
\text { Female }\end{array}$ & $\begin{array}{r}39(81.2) \\
9(18.8)\end{array}$ & $\begin{array}{l}39(79.6) \\
10(20.4)\end{array}$ & 0.168 \\
\hline Age (years \pm SD) & $58 \pm 8$ & $54 \pm 8$ & 0.014 \\
\hline $\mathrm{BMI}\left(\mathrm{Kg} / \mathrm{m}^{2} \pm \mathrm{SD}\right)$ & $24.8 \pm 2.8$ & $25.9 \pm 3.6$ & 0.093 \\
\hline $\mathrm{SBP}(\mathrm{mmHg} \pm \mathrm{SD})$ & $120 \pm 23$ & $127 \pm 20$ & 0.132 \\
\hline $\mathrm{DBP}(\mathrm{mmHg} \pm \mathrm{SD})$ & $77 \pm 14$ & $79 \pm 11$ & 0.354 \\
\hline HR (times/minutes \pm SD) & $86 \pm 23$ & $81 \pm 26$ & 0.312 \\
\hline $\begin{array}{l}\text { Risk Factor }(\mathrm{n}, \%) \\
\text { Diabetes Mellitus } \\
\text { Hypertension } \\
\text { Dyslipidaemia } \\
\text { Smoking } \\
\text { Family History of CAD }\end{array}$ & $\begin{array}{l}21(43.8) \\
36(75) \\
30(62.5) \\
35(72.9) \\
3(6.3)\end{array}$ & $\begin{array}{l}14(28.6) \\
34(69.4) \\
28(57.1) \\
29(59.2) \\
6(12.2)\end{array}$ & $\begin{array}{l}0.12 \\
0.537 \\
0.591 \\
0.153 \\
0.487\end{array}$ \\
\hline $\begin{array}{l}\text { Diagnosis }(\mathrm{n}, \%) \\
\text { STEMI } \\
\text { NSTEMI } \\
\text { UAP }\end{array}$ & $\begin{array}{l}21(43.8) \\
22(45.8) \\
5(10.4) \\
\end{array}$ & $\begin{array}{l}19(38.8) \\
16(32.7) \\
14(28.6)\end{array}$ & 0.071 \\
\hline $\begin{array}{l}\text { Laboratory } \\
\mathrm{Hb}(\mathrm{mg} / \mathrm{dL} \pm \mathrm{SD})\end{array}$ & $13.2 \pm 1.8$ & $14.1 \pm 1.6$ & 0.012 \\
\hline
\end{tabular}




\begin{tabular}{|c|c|c|c|}
\hline $\begin{array}{l}\text { Ht }(\% \pm \mathrm{SD}) \\
\text { WBC count }\left(10^{3} / \mathrm{uL} \pm \mathrm{SD}\right) \\
\text { Platelet count }\left(10^{3} / \mathrm{mm}^{3} \pm \mathrm{SD}\right) \\
\text { RDW }(\% \pm \mathrm{SD}) \\
\text { MPV }(\mathrm{fL} \pm \mathrm{SD}) \\
\text { PDW }(\% \pm \mathrm{SD}) \\
\text { Monosit count }\left(10^{3} / \mathrm{uL} \pm \mathrm{SD}\right) \\
\text { MHR }(\mathrm{n} \pm \mathrm{SD}) \\
\text { Neutrophilecount }\left(10^{3} / \mathrm{uL} \pm \mathrm{SD}\right) \\
\text { Lymphocytecount }\left(10^{3} / \mathrm{uL} \pm \mathrm{SD}\right) \\
\text { NLR }(\mathrm{n} \pm \mathrm{SD}) \\
\text { Urea }(\mathrm{mg} / \mathrm{dL} \pm \mathrm{SD}) \\
\text { Serum Creatinine }(\mathrm{mg} / \mathrm{dL} \pm \mathrm{SD}) \\
\text { GFR }\left(\mathrm{mL} / \mathrm{min} / 1.73 \mathrm{~m}^{2} \pm \mathrm{SD}\right) \\
\text { Random BG }(\mathrm{mg} / \mathrm{dL} \pm \mathrm{SD}) \\
\text { Fasting BG }(\mathrm{mg} / \mathrm{dL} \pm \mathrm{SD}) \\
\text { PostprandialBG }(\mathrm{mg} / \mathrm{dL} \pm \mathrm{SD}) \\
\text { HbA1c }(\% \pm \mathrm{SD}) \\
\text { Total Cholesterol }(\mathrm{mg} / \mathrm{dL} \pm \mathrm{SD}) \\
\text { LDL-C }(\mathrm{mg} / \mathrm{dL} \pm \mathrm{SD}) \\
\text { HDL-C }(\mathrm{mg} / \mathrm{dL} \pm \mathrm{SD}) \\
\text { Trygliceride }(\mathrm{mg} / \mathrm{dL} \pm \mathrm{SD})\end{array}$ & $\begin{array}{l}39.3 \pm 15.4 \\
11.9 \pm 4.3 \\
256.8 \pm 68.7 \\
13.2 \pm 0.9 \\
10 \pm 0.9 \\
11.3 \pm 1.6 \\
1.03 \pm 0.3 \\
0.033 \pm 0.015 \\
8.5 \pm 3.7 \\
2.3 \pm 1 \\
4.4 \pm 2.7 \\
37.5 \pm 28 \\
1.3 \pm 0.9 \\
68.1 \pm 24.9 \\
175 \pm 97 \\
138 \pm 66 \\
168 \pm 69 \\
7.2 \pm 2 \\
182 \pm 46 \\
119 \pm 41 \\
34 \pm 13 \\
142 \pm 50\end{array}$ & $\begin{array}{l}41.7 \pm 4.3 \\
10.9 \pm 3.4 \\
262.1 \pm 65.7 \\
13.2 \pm 0.8 \\
9.9 \pm 0.7 \\
11.3 \pm 1.5 \\
0.7 \pm 0.2 \\
0.021 \pm 0.008 \\
7.3 \pm 3.3 \\
2.4 \pm 0.9 \\
3.6 \pm 2.6 \\
31.3 \pm 17.4 \\
1.1 \pm 0.6 \\
79.5 \pm 32.5 \\
136 \pm 58 \\
120 \pm 56 \\
156 \pm 78 \\
6.6 \pm 1.6 \\
191 \pm 43 \\
126 \pm 42 \\
37 \pm 8 \\
165 \pm 81\end{array}$ & $\begin{array}{l}0.020 \\
0.227 \\
0.699 \\
0.976 \\
0.625 \\
0.832 \\
0.000 \\
0.006 \\
0.110 \\
0.618 \\
0.158 \\
0.188 \\
0.385 \\
0.055 \\
0.019 \\
0.143 \\
0.433 \\
0.114 \\
0.347 \\
0.458 \\
0.215 \\
0.108\end{array}$ \\
\hline $\begin{array}{l}\text { Ejection Fraction } \\
\text { LVEF }(\% \pm \mathrm{SD}) \\
\mathrm{LVEF}<50 \%(\mathrm{n} \pm \mathrm{SD})\end{array}$ & $\begin{array}{l}42 \pm 11 \\
33(68.8) \\
\end{array}$ & $\begin{array}{l}45 \pm 10 \\
30(61.2)\end{array}$ & $\begin{array}{l}0.183 \\
0.437 \\
\end{array}$ \\
\hline $\begin{array}{l}\text { TIMI risk score }(\mathrm{n}, \%) \\
\text { Moderate to High Risk } \\
\text { Low Risk }\end{array}$ & $\begin{array}{l}44(91.7) \\
4(8.3)\end{array}$ & $\begin{array}{l}33(67.3) \\
16(32.7)\end{array}$ & 0.003 \\
\hline $\begin{array}{l}\text { Coronary Lesion (n, \%) } \\
\text { Non-Significant } \\
1 \text { VD } \\
2 \text { VD } \\
3 \text { VD }\end{array}$ & $\begin{array}{l}0(0) \\
4(8.3) \\
19(39.6) \\
25(52.1)\end{array}$ & $\begin{array}{l}10(20.4) \\
25((51) \\
9(18.4) \\
5(10.2)\end{array}$ & 0.000 \\
\hline Gensini Score $(\mathrm{n} \pm \mathrm{SD})$ & $69 \pm 30$ & $15 \pm 9$ & 0.000 \\
\hline
\end{tabular}

The correlation analysis of clinical parameters based on the severity of coronary artery lesions was found to be several parameters with significant associations that had a positive correlation with Gensini score, ie age, monocyte, MHR, random glucose test, TIMI score, and coronary lesions. There was a significant correlation but with a weak correlation between MHR and the severity of coronary artery lesions based on Gensini score $(\mathrm{p}=0.006)(\mathrm{r}=0.252)$ (Table 2).

Table 2. Correlation between MHR and Gensini Score

\begin{tabular}{|l|l|l|l|l|}
\hline Variable & High Gensini Score $(\mathbf{n}=\mathbf{4 8})$ & Low Gensini Score $(\mathbf{n}=\mathbf{4 9})$ & P value & P pearson \\
\hline MHR & $0,033 \pm 0,15$ & $0,02 \pm 0,008$ & $0,006^{*}$ & 0,252 \\
\hline
\end{tabular}

Using the ROC curve, we can assess the under the curve area (AUC) of the MHR parameter, which will demonstrate MHR's ability to influence the severity of coronary artery lesions in patients with ACS. In this study found AUC 0.725 with $\mathrm{p}$ value $<0.05$ (Figure 1). This suggests that the MHR value is clinically significant relative to the severity of coronary artery lesions in patients with ACS. The MHR value > 0.021 becomes the best cutoff point in predicting the severity of coronary artery lesions (Table 3 ). 


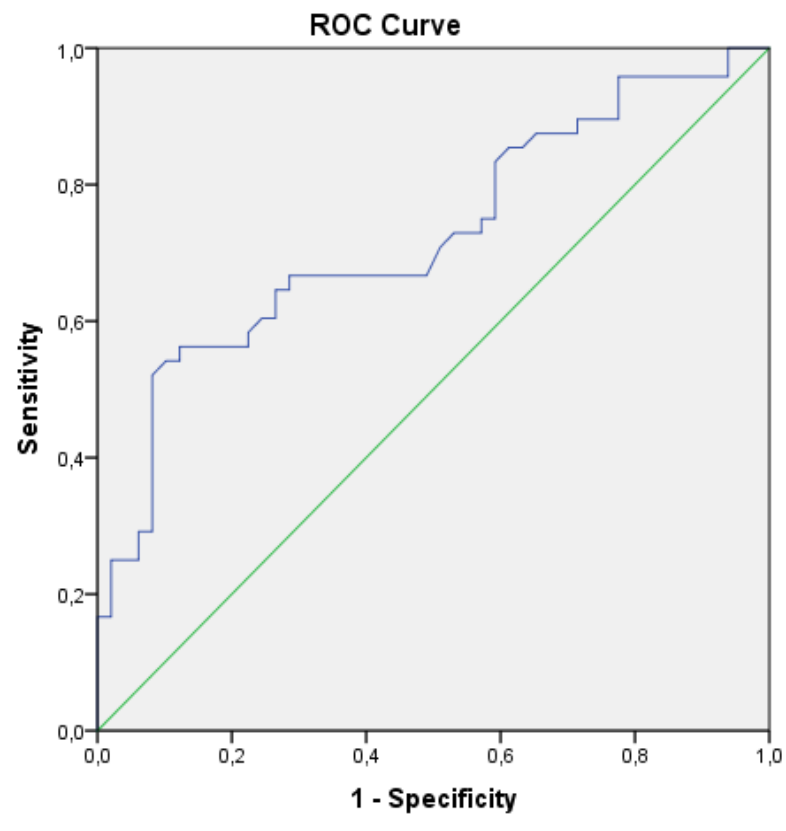

Diagonal segments are produced by ties.

Figure 1.ROC Curve of MHR in predicting severity of coronary artery lesions

Table 3.Results from ROC analysis

\begin{tabular}{|l|l|l|l|l|l|}
\hline Cut-off Point & Sens & Spes & AUC & P value & 95\% CI \\
\hline 0.021 & $70.8 \%$ & $51 \%$ & 0.725 & $<0.046$ & $0.623-0.827$ \\
\hline
\end{tabular}

Of 97 subjects it was found that 58 patients had MHR $\geq 0.021$ and 39 patients had MHR $<0.021$. The subjects in the group with MHR $\geq 0.021$ had more severe coronary artery lesions than the group with MHR $<$ 0.021 , which is 34 patients (70.8\%) versus 14 patients (29.2\%). While in the group with MHR $<0.021$ had less severe coronary artery lesions than the group with MHR $\geq 0.021$. The MHR value of $\geq 0.021$ can predict the severity of coronary artery lesions with $70.8 \%$ sensitivity, $51 \%$ specificity, $64.1 \%$ negative predictive value (NPV) and 58.6\% positive predictive value (PPV)(Table 4).

Table 4.Diagnostic test of MHR Cut-off Point

\begin{tabular}{|c|c|c|c|c|c|c|c|c|}
\hline \multirow[t]{2}{*}{ MHR } & \multicolumn{2}{|c|}{ Coronary Lesions } & \multirow[t]{2}{*}{ Total } & \multirow[t]{2}{*}{$P$ value } & \multirow[t]{2}{*}{ Sens } & \multirow[t]{2}{*}{ Spes } & \multirow[t]{2}{*}{ NPV } & \multirow[t]{2}{*}{ PPV } \\
\hline & Severe & Mild & & & & & & \\
\hline$\geq 0.021$ & $\begin{array}{l}34 \\
(70.8)\end{array}$ & $\begin{array}{l}24 \\
(49)\end{array}$ & $\begin{array}{l}58 \\
(59.8)\end{array}$ & \multirow[t]{3}{*}{$<0.046$} & \multirow[t]{3}{*}{$70.8 \%$} & \multirow[t]{3}{*}{$51 \%$} & \multirow[t]{3}{*}{$64.1 \%$} & \multirow[t]{3}{*}{$58.6 \%$} \\
\hline$<0.021$ & $\begin{array}{l}14 \\
(29.2)\end{array}$ & $\begin{array}{l}25 \\
(51)\end{array}$ & $\begin{array}{l}39 \\
(40.2)\end{array}$ & & & & & \\
\hline Total & $\begin{array}{l}48 \\
(100)\end{array}$ & $\begin{array}{l}49 \\
(100)\end{array}$ & $\begin{array}{l}97 \\
(100)\end{array}$ & & & & & \\
\hline
\end{tabular}

Multivariate analysis in this study is useful to know which independent variables are the most dominant and influential to determine the severity of coronary artery lesions in patients with ACS. Based on the comparative test table, there are 21 parameters with $\mathrm{p}$ value $<0.25$ which will be tested by logistic regression to obtain the best parameters related to the severity of coronary artery lesions on a multivariate basis.

From 17 multivariate analysis steps using logistic regression involving 21 clinical parameters, two significant parameters were found to correlate with the severity of coronary artery lesion, moderate to high TIMI risk score [OR: 4.682 (1.445-15.168), $\mathrm{p}<0.01$ ] and values RMH> 0.021 [OR: 2.68 (1.069-6.716), $\mathrm{p}=$ 0.035] (Table 5). 
Table 5. Multivariate Logistic Regression Analysis of MHR to Predict Severity of Coronary Artery Lesions

\begin{tabular}{|l|l|l|l|}
\hline Variable & P value & OR & 95\% CI \\
\hline TIMI Risk Score Moderate to High & $<0.01$ & 4.682 & $1.445-15.168$ \\
\hline MHR $\geq 0.021$ & 0.035 & 2.68 & $1.069-6.716$ \\
\hline
\end{tabular}

\section{Discussion}

Subjects in this study were collected consecutively from patients diagnosed with ACS undergoing coronary angiography procedure during hospitalization from January 2015 to April 2018. There were 97 patients who have met the inclusion and exclusion criteria.

In this study found that groups with high Gensini scores had a higher age than the group with low Gensini score with a value of $p<0.05$. Monocyte values were also higher in the high Gensini score group than in the low Gensini score group. Higher MHR value and TIMI scores were found in group with high Gensini score.

Previous studies have shown similar results, where the parameters of age, monocyte and age are higher in the group with more severe coronary artery lesion. ${ }^{20,21}$

In patients with STEMI there will be a total blockage of the coronary arteries that causes loss of perfusion to the myocardium thus triggering myocardial damage and acute inflammatory reactions. ${ }^{22}$ Likewise in NSTEMI and UAP patients, but because the blockage is a subtotal obstruction, then myocardial damage and acute inflammatory reactions are not as strong in patients with IMAEST. Nazowa et al has shown a relationship between the number of circulating monocytes with the progression of coronary plaque after acute coronary syndrome. ${ }^{9}$ Another study by Olivares et al has reported a high monocyte count to be a predictor of coronary events with 7 years of assessment. ${ }^{23}$

HDL has an effect that is thought to inhibit monocyte activation. Murphy et al have shown that activated monocytes may be inhibited by HDLs that have anti-inflammatory, anti-oxidant and anti-thrombotic effects. $^{24,25}$ HDL cholesterol also has a close interaction with monocytes through suppression of monocyte activity, inhibiting monocyte differentiation into macrophages that ultimately limiting the inflammatory response. $^{26}$

In this study, an MHR value analysis was performed in predicting the severity of coronary artery lesions based on Gensini score on patients with ACS. There was a significant relationship but with a weak correlation between MHR and the severity of coronary artery lesions based on Gensini score ( $\mathrm{p}=0.006)$ $(\mathrm{r}=0.252)$. In the previous study also found the relationship of MHR with the severity of coronary artery lesions in ACS and stable CHD patients, also with a weak correlation $(\mathrm{p}<0.001)(\mathrm{r}=0.159) .{ }^{20}$

By using ROC curve, value of AUC was 0.725 with $p$ value $<0.05$. This suggests that the MHR value is clinically significant relative to the severity of coronary artery lesions in patients with ACS. The value of MHR $>0.021$ becomes the best cutoff point in predicting the severity of coronary artery lesions. Then in this study, based on multivariate analysis, 2 parameters were found that correlated with the severity of coronary artery lesion, moderate to high TIMI risk score and MHR value $>0.021$.

In the previous study, there was a correlation between MHR and coronary lesion complexity with MHR cutoff value of 0.024 , but this study assessed the complexity of coronary artery lesion by using SYNTAX score in stable CHD patient population. In this study also obtained the value of CRP, MHR and LVEF become independent factors in predicting the complexity of coronary lesions. ${ }^{27}$

In this study found a significant relationship but with a weak correlation between the MHRvalue with the severity of coronary artery lesions assessed by Gensini score. This raises the question of determining the use of MHR in clinical practice.In the previous study described two things, namely the sub-type of monocytes and also about the sub-class of HDL. The circulating monocyte sub-type has heterogeneous function, and each subtype has different inflammatory potential effects as well. So a simple monocyte count does not actually describe the activation status of monocytes. Then the anti-atherogenic properties of the HDL subclass are considered to have differences and there is no evidence to indicate which sub-classes are dominant to have such effects. ${ }^{20,28,29}$ 
In this study used simple MHR parameters and did not evaluate sub-class HDL or sub-type monocytes. Previous studies have suggested simple MHR parameters can be used as markers of inflammation and cardiovascular risk.

Conflict of interest: None declared.

\section{References}

1. World Health Organization (WHO). Cardiovascular diseases (CVDs), fact sheet. 2017. Available from: http://www.who.int/mediacentre/factsheets/fs317/en/

2. Yusuf S, Reddy S, Ounpuu S, et al. Global burden of cardiovascular diseases, part I: general consideration, the epidemiologic transition, risk factors, and impact of urbanization. Circulation 2001;104:2753-64

3. Hansson GK. Inflammation, atherosclerosis, and coronary artery disease. N Engl J Med 2005;352:168595

4. Hilgendorf I, Swirski FK, Robbins CS. Monocyte fate in atherosclerosis. ArteriosclerThromb Vasc Biol 2015;Mar:35:272-9

5. Buja LM, Willerson JT. Role of Inflammation in Coronary Plaque Disruption. Circulation 1994;89:503-5

6. Mazzone A, et al. Increased Expression of Neutrophil and Monocyte Adhesion Molecules in Unstable Coronary Artery Disease. Circulation 1993;88:358-63

7. Mehta J, et al. Neutrophil Function in Ischemic Heart Disease. Circulation 1989;79:549-56

8. $\quad$ Ross R. Atheroslerosis-An inflammatory disease. N Engl J Med 1999;340:115-26

9. Nozawa N, Hibi K, Endo M, et al. Association between circulatingmonocytes and coronary plaque progression in patientswith acute myocardial infarction. Circ J 2010;74(7):1384-91

10. Afiune NA, Mansur AP, Avakian SD, et al. Monocytosis is an independent risk marker for coronary artery disease. Arq Bras Cardiol 2006;86(3):240-4

11. Bath PM, Gladwin A-M, Martin JF. Humanmonocyte characteristics are altered in hypercholesterolaemia. Atherosclerosis 1991;90(2):175-81

12. Parthasarathy S, Barnett J, Fong LG. High-density lipoprotein inhibits the oxidative modification of low-density lipoprotein. Biochim Biophys Acta 1990;1044:275-83

13. Hafiane A, Genest J. High density lipoproteins: measurementtechniques and potential biomarkers of cardiovascular risk. BBAClin 2015;3:175-88

14. Wang N, Lan D, Chen W, et al. ATP-binding cassette b transporters G1 and G4 mediate cellular cholesterol efflux to high-density lipoproteins. Proc Natl Acad Sci USA 2004; 101:9774-9

15. Westerterp M, Gourion-Arsiquaud S, Murphy AJ, et al. Regulation of hematopoietic stem and progenitor cell mobilization by cholesterol efflux pathways. Cell Stem Cell 2012; 11:195-206

16. Canpolat U, Çetin EH, Cetin S, et al. Association of monocyte-to-HDL cholesterol ratio with slow coronary flow islinked to systemic inflammation. Clin Appl Thromb Hemost 2016;22:476-82

17. Cetin MS, Cetin EHO, Kalender E, et al. Monocyte to HDL Cholesterol Ratio Predicts Coronary Artery Disease Severity and Future Major Cardiovascular Adverse Events in Acute Coronary Syndrome. Heart Lung and Circulation 2016;1-10

18. Sullivan DR, Marwick TH, Freedman SB. A new method of scoring coronary angiograms to reflectextent of coronary atherosclerosis and improve correlation with major risk factors. American heart journal 1990; 119(6):1262-7

19. Kaya H, Ertas F, Islamoglu Y. Association Between Neutrophil and Lymphocyte Ratio and Severity of Coronary Artery Disease. Clinical and Applied Thrombosis/Hemostasis 2014;20(1):50-54

20. Kiziltune E, Alsancak Y, Sezenoz B, et al. Relationship between monocyte/high-density lipoprotein cholesterol ratio and angiographic severity and extent of coronary artery disease. Kosuyolu Heart $J$ 2017;20(1):30-5

21. Zhang Y, Li S, Guo Y, et al. Is monocyte to HDL ratio superior to monocyte count in predicting the cardiovascular outcomes: evidence from a large cohort of Chinese patients undergoing coronary angiography.Annals of Medicine 2016;1-8

22. Kirtane AJ, Bui A, Murphy SA, et al. Association of peripheral neutrophilia with adverse angiographic outcomes in ST-elevation myocardial infarction. Am J Cardiol 2004;93:532-6

23. Olivares R, Ducimetière P, Claude JR. Monocytecount: a risk factor for coronary heart disease?.Am J Epidemiol 1993;137(1):49-53 
24. Ghattas A, Griffiths HR, Devitt A, et al. Monocytesin coronary artery disease and atherosclerosis: where are we now? JAm Coll Cardiol 2013;62:1541-51

25. Murphy AJ, Woollard KJ. High-density lipoprotein: a potent inhibitor of inflammation. Clin Exp Pharmacol Physiol 2010;37:710-18

26. Murphy AJ, Woollard KJ, Hoang A, et al. High-density lipoprotein reduces the human monocyte inflammatory response. Arterioscler Thromb Vasc Biol 2008; 28:2071-7

27. Kundi H, Kiziltunc E, Cetin M, et al.Association of monocyte/HDL-C ratio with SYNTAX scores in patientswith stable coronary artery disease. Herz 2016;41:523-9

28. Superko HR, Pendyala L, Williams PT, Momary KM, King SB 3rd, Garrett BC. High-density lipoprotein subclasses and their relationship to cardiovascular disease. J Clin Lipidol 2012;6:496-523

29. Chelombitko MA, Shishkina VS, Ilyinskaya OP, et al. A cytofluorometric study of membrane rafts in human monocyte subsets in atherosclerosis. Acta Naturae 2014;6:80-8 